\title{
Insulin-like growth factor I promotes adipogenesis in hemangioma stem cells from infantile hemangiomas
}

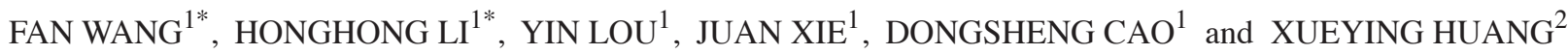 \\ ${ }^{1}$ Department of Plastic Surgery, The Second Affiliated Hospital of Anhui Medical University; \\ ${ }^{2}$ Department of Anatomy, Anhui Medical University, Hefei, Anhui 230601, P.R. China
}

Received May 4, 2018; Accepted November 29, 2018

DOI: $10.3892 / \mathrm{mmr} .2019 .9895$

\begin{abstract}
Infantile hemangiomas ( $\mathrm{IH})$ are the most common infantile neoplasms and are characterized by initial proliferation during infancy and subsequent spontaneous regression within the next 5-10 years, frequently leaving fibrous fat residues. However, the specific mechanisms underlying the differentiation of hemangioma stem cells (HemSCs) into adipocytes are not clear. The purpose of the present study was to investigate the effect of insulin-like growth factor I (IGF-1) on HemSCs from patients with $\mathrm{IH}$ and to determine the signaling mechanisms involved. Treatment of HemSCs with IGF-1 led to upregulation of the protein expression levels of peroxisome proliferator-activated receptor- $\gamma$ (PPAR $\gamma)$. By contrast, inhibition of the IGF-1 receptor (IGF-1R) or phosphoinositide 3-kinase (PI3K) activity decreased the expression of PPAR $\gamma$, in addition to that of CCAAT/enhancer-binding protein $(\mathrm{C} / \mathrm{EBP}) \alpha, \mathrm{C} / \mathrm{EBP} \beta$, and adiponectin. IGF-1 upregulated the expression of phosphorylated RAC- $\alpha$ serine/threonine-protein kinase in IH cells, whereas a specific PI3K inhibitor or IGF-1R antibody blocked this effect. These results indicated that IGF-1 is a pro-proliferative and pro-lipogenic factor in $\mathrm{IH}$ HemSCs. Taken together, these findings indicated that IGF-1 is able to upregulate PPAR $\gamma$ by activating the IGF-1R and PI3K pathways, thereby accelerating lipogenesis and enhancing $\mathrm{IH}$ HemSC adipogenesis.
\end{abstract}

Correspondence to: Professor Dongsheng Cao, Department of Plastic Surgery, The Second Affiliated Hospital of Anhui Medical University, 678 Furong Road, Hefei, Anhui 230601, P.R. China

E-mail: dscao1966@126.com

Professor Xueying Huang, Department of Anatomy, Anhui Medical University, 81 Meishan Road, Hefei, Anhui 230601, P.R. China

E-mail: hxy8676@126.com

*Contributed equally

Key words: insulin-like growth factor 1, hemangioma stem cells, proliferation, adipogenesis, infantile hemangiomas

\section{Introduction}

Infantile hemangiomas (IHs), the most common neoplasms in infants, are characterized by their early appearance following birth and their eventual regression over time. These benign tumors are estimated to occur in approximately $4-5 \%$ of the general population $(1,2)$ and are usually harmless. However, a small percentage of these tumors are destructive, disfiguring and even life-threatening, depending on their size and location (3). At present, the primary candidate for cellular sources of IHs are hemangioma stem cells (HemSCs), and cluster of differentiation (CD) $133^{+} \mathrm{HemSCs}$ also differentiate into a number of cell lineages, including adipocytes $(4,5)$. For this reason, investigating the mechanism of adipogenesis in HemSCs is of considerable clinical interest.

One potential regulator\$ of HemSC adipogenesis is insulin-like growth factor 1 (IGF-1), since expression of this polypeptide in the majority of tissues is known to regulate adipogenesis (6). IGF-1 activity is mediated by the IGF-1 receptor (IGF-1R), a member of the tyrosine kinase family of growth factor receptors that contains two extracellular $\alpha$-subunits and two membrane-spanning $\beta$-subunits that constitute an intracellular tyrosine kinase (7). IGF-1 controls the mass of adipose tissue by regulating adipogenesis (8), and it is also known to stimulate fat formation $(9,10)$. Binding of IGF-1 to its receptor upregulates the phosphorylation of cyclic AMP-responsive element-binding protein (CREB) through the phosphoinositide 3-kinase (PI3K)/RAC- $\alpha$ serine/threonine-protein kinase (AKT) pathway (9). Activated CREB increases the expression of peroxisome proliferator-activated receptor- $\gamma 2$ (PPAR $\gamma 2$ ), a key factor that directs the differentiation of adipocytes by controlling the expression of specific differentiation-associated adipocyte genes $(6,11)$. Other studies have demonstrated that IGF-1 promotes adipocyte proliferation and differentiation from adipose stromal cells and human mesenchymal stem cells $(12,13)$. The effect of IGF-1 on HemSCs in IH is currently unclear.

The present study investigated the function of IGF-1 in HemSC proliferation and adipogenesis in IH. The PI3K signaling cascades in HemSCs were also studied to obtain a better understanding of the possible signaling mechanisms that may be involved and that may be used to develop new therapeutic approaches for the treatment of patients with IH. 


\section{Materials and methods}

Preparation of hemangioma specimens. Ethics committee approval was obtained for the collection of abscised human hemangiomas from The Second Affiliated Hospital of Anhui Medical University (Hefei, China; no. PJ-bb2017-026). The tissues were immediately used for cell isolation and culture for in vitro experiments.

Isolation and identification of HemSCs. The proliferating IH tissues removed from the patients were immediately immersed in growth medium consisting of high glucose Dulbecco's modified Eagle's medium (GE Healthcare Life Sciences, Shanghai, China), 10\% fetal bovine serum (FBS; Gibco; Thermo Fisher Scientific, Inc., Waltham, MA, USA), and $1 \%$ penicillin-streptomycin (PS; Beyotime Institute of Biotechnology, Haimen, China) at $4^{\circ} \mathrm{C}$ and quickly taken to the laboratory. The fat or skin tissues were removed and the samples were rinsed three times in PBS. The tissues were minced and digested with $0.2 \%$ collagenase (SERVA Electrophoresis $\mathrm{GmbH}$, Heidelberg, Germany) at $37^{\circ} \mathrm{C}$ for $2 \mathrm{~h}$ until the samples were chylous, and were passed through a $100-\mu \mathrm{m}$ cell strainer. The cells expressing CD133 were separated from the resulting single-cell suspension using a magnetic bead technique (Miltenyi Biotec, Inc., Auburn, CA, USA) and cultured on fibronectin-coated plates in endothelial growth medium-2 (EGM-2; Lonza Group, Ltd., Basel, Switzerland) supplemented with $20 \%$ FBS and $1 \%$ PS in a $37^{\circ} \mathrm{C}$ incubator with $5 \% \mathrm{CO}_{2}$.

Proliferation assay. HemSCs in the logarithmic growth phase were seeded into 96-well tissue culture plates (Corning, Inc., Corning, NY, USA) at an initial density of $2 \times 10^{3}$ cells. After $24 \mathrm{~h}$ of serum starvation, IGF-1 (Peprotech, Inc., Rocky Hill, NJ, USA), dissolved in EBM-2 containing 5\% FBS, was added at $0,10,20,100$ and $200 \mathrm{ng} / \mathrm{ml}$. After $72 \mathrm{~h}$ of culture, Cell Counting kit-8 (CCK-8) reagent (Dojindo Molecular Technologies, Inc., Kumamoto, Japan) was added to each well and the absorbance at $490 \mathrm{~nm}$ was read using a microplate reader (BioTek ELx 800; BioTek Instruments, Inc., Winooski, VT, USA).

The growth kinetics of IGF-1-treated HemSCs were examined by seeding HemSCs into 96-well plates (Corning, Inc.) at a density of $1.5 \times 10^{3}$ cells/well. Following serum starvation, the cells were treated with $100 \mathrm{ng} / \mathrm{ml} \mathrm{IGF-1} \mathrm{containing} \mathrm{5 \%} \mathrm{FBS.}$ CCK- 8 was added after $0,1,3,5$ and 7 days of culture and the cells were incubated at $37^{\circ} \mathrm{C}$ for a further $4 \mathrm{~h}$. The optical density at $490 \mathrm{~nm}$ was measured with a microplate reader (BioTek ELx 800).

Immunohistochemistry. Cells $\left(1 \times 10^{4}\right)$ cultured on coverslips were fixed in $4 \%$ poly-formaldehyde for $15 \mathrm{~min}$ at room temperature. Following air-drying for $5 \mathrm{~min}$, the cells were permeabilized in $0.5 \%$ Triton X-100 for $10 \mathrm{~min}$. Endogenous peroxidase activity was inactivated by treatment with $3 \%$ hydrogen peroxide at room temperature for 5-10 min. The slides were blocked with 10\% FBS for 15-20 min at room temperature, and the blocking solution was aspirated without further washing. The cells were washed with PBS, and the slides were incubated overnight at $4^{\circ} \mathrm{C}$ with the following primary antibodies: Anti-IGF-1 (1:500, cat. no. bs-0014R), anti-IGF-1R (1:500, cat. no. bs-0227R) and anti- $\beta$-actin (1:500, cat. no. bs-0016R; all BIOSS, Beijing, China). Antibodies were replaced with PBS in the negative control group. Horseradish peroxidase-conjugated secondary antibody working solution (cat. no. PV-6000; OriGene Technologies, Inc., Beijing, China) were incubated for $10-15 \mathrm{~min}$ at $37^{\circ} \mathrm{C}$. The cells were observed by bright-field microscopy (x400) for 3-10 min immediately following addition of diaminobenzidine (DAB) solution (50 $\mu \mathrm{l}$ DAB:1 ml DAB substrate; stored in the dark). The cells were hematoxylin-stained for $0.5-1 \mathrm{~min}$ at room temperature, and gum-sealed following drying. The cells were photographed under bright field illumination (x400, Olympus IX71; Olympus Corporation, Tokyo, Japan).

Oil Red $O$ staining. The adipogenic differentiation of IGF-1-treated HemSCs was evaluated by seeding $5.0 \times 10^{4}$ cells in 6-well plates in EGM-2/10\% FBS. When cells were oversaturated, the original medium was switched to an adipogenic differentiation media (Cyagen Biosciences, Inc., Santa Clara, CA, USA) containing either IGF-1 (100 ng/ml), IGF-1 $(100 \mathrm{ng} / \mathrm{ml})$ plus OSI-906 (1 $\mu \mathrm{M}$; Selleck Chemicals, Houston, TX, USA; an IGF-1R inhibitor), IGF-1 (100 ng/ml) plus LY294002 (10 $\mu \mathrm{M}$; MedChemExpress, Monmouth Junction, NJ, USA), LY294002 (10 $\mu \mathrm{M}$; MedChemExpress; PI3K inhibitor), or no treatment, and the cells were incubated for 10 days. At room temperature, the cells were washed gently with PBS twice, fixed with $4 \%$ fresh formaldehyde in PBS for $15 \mathrm{~min}$ and stained with Oil Red $\mathrm{O}$ for $30 \mathrm{~min}$. Cells were examined with an inverted microscope (x200), and the numbers determined using Image $\mathrm{J}$ software $(1.51 \mathrm{~s}$; National Institutes of Health, Bethesda, MD, USA). The cells were photographed using an Eclipse E800 microscope (Nikon Corporation, Tokyo, Japan).

Western blotting. HemSCs were grown on $10-\mathrm{cm}$ tissue culture plates (Corning, Inc.) in EGM-2/10\% FBS containing IGF-1 (100 ng/ml), IGF-1 (100 ng/ml) plus OSI-906 (1 $\mu \mathrm{M})$, IGF-1 (100 ng/ml) plus LY294002 (10 $\mu \mathrm{M})$, or no treatment. Total protein was extracted using radioimmunoprecipitation assay lysis buffer ( $1 \mathrm{mM}$; BIOSS), and protein concentration was determined with a Bradford Protein Assay kit (Beyotime Institute of Biotechnology). Cell protein extracts $(5 \mu \mathrm{l} /$ lane) were subjected to SDS-PAGE on $10 \%$ polyacrylamide gels. The samples were transferred to polyvinylidene fluoride membranes, which were blocked with $5 \%$ skim milk for $2 \mathrm{~h}$, incubated with primary antibodies overnight at $4^{\circ} \mathrm{C}$, and subsequently incubated with IRDye 800CW-conjugated goat anti-rabbit IgG secondary antibody (cat. no. bs-40295G-IRDye8; 1:20,000; BIOSS) for $1 \mathrm{~h}$ at room temperature. The primary antibodies were: Anti-PPAR $\gamma$ (cat. no. bs-0530P; 1:500; BIOSS), anti-CCAAT/enhancer-binding protein $(\mathrm{C} / \mathrm{EBP} \alpha$; cat. no. bs-0016R; 1:1,000), anti-C/EBP $\beta$ (cat. no. bs-1396R; 1:1,000), anti-adiponectin (cat. no. bs-0471R; 1:1,000; BIOSS), anti-IGF-1 (cat. no. bs-0014R; 1:1,000; all BIOSS), anti-phosphorylated (p)AKT (cat. no. 9271; 1:500), anti-AKT (cat. no. 9272; 1:500) and anti- $\beta$-actin (cat. no. 3700; 1:500; all Cell Signaling Technology, Inc., Danvers, MA, USA). 
Finally, the signal was detected using enhanced chemiluminescence reagents (Beyotime Institute of Biotechnology), and band density was analyzed with Image J software (1.51s; National Institutes of Health, Bethesda, MD, USA).

Statistical analyses. The data are expressed as the mean \pm standard deviation ( $n=3$ for each experiment). SPSS version 23 (IBM Corp., Armonk, NY, USA) was used to perform statistical analysis. Where appropriate, an unpaired Student's t-test was used to assess the differences between two groups, and one-way analysis of variance followed by Fisher's Least Significant Difference test was applied for the analysis of the mean values among multiple groups. $\mathrm{P}<0.05$ was considered to indicate a statistically significant difference.

\section{Results}

IGF-1 promotes cell proliferation in IH HemSCs. The CCK-8 assay was performed to determine whether IGF-1 affected in vitro HemSC proliferation. The addition of IGF-1 at $100-200 \mathrm{ng} / \mathrm{ml}$ stimulated the proliferation of HemSCs, with the $100 \mathrm{ng} / \mathrm{ml}$ concentration exhibiting the best response among all the groups (Fig. 1A). Cell growth curves confirmed that treatment with $100 \mathrm{ng} / \mathrm{ml} \mathrm{IGF-1} \mathrm{promoted} \mathrm{cell} \mathrm{proliferation}$ between days 3 and 7 when compared with the non-treatment group (Fig. 1B).

Expression of IGF-1 and IGF-1R in HemSCs. Fig. 2A presents the positive expression of IGF-1 and IGF-1R in HemSCs. IGF-1 was localized primarily to the cytoplasm, while IGF-1R was localized to the cytoplasm and the cell membrane.

IGF-1 promotes the differentiation of HemSCs into adipocytes and enhances lipogenesis. The HemSCs exhibited increased cell numbers and greater lipid droplet density when treated with adipogenic differentiation medium containing IGF-1, compared with adipogenic differentiation medium alone or with media containing IGF-1 plus OSI-906, IGF-1 plus LY294002, or LY294002 alone (Fig. 2B). The IGF-1 treatment thus appeared to stimulate adipogenesis and lipid accumulation in the HemSCs, whereas treatment with the OSI-906 IGF-1R inhibitor or LY294002, a specific inhibitor of PI3K, suppressed this IGF-1-induced lipid accumulation.

OSI-906 and LY294002 suppress IGF-1-enhanced adipogenic differentiation and AKT protein phosphorylation. Western blotting confirmed an increase in $\mathrm{C} / \mathrm{EBP} \alpha, \mathrm{C} / \mathrm{EBP} \beta$, PPAR $\gamma$ and adiponectin expression in response to IGF-1 when compared with the control group. This increase in transcription factors and adipocyte-specific proteins indicated that IGF-1 enhanced adipogenesis in HemSCs and this enhancement was suppressed in the presence of OSI-906 or LY294002. In addition, LY294002 alone was able to suppress $\mathrm{HemSC}$ adipogenesis and inhibit the expression of $\mathrm{C} / \mathrm{EBP} \alpha$, $\mathrm{C} / \mathrm{EBP} \beta, \operatorname{PPAR} \gamma$ and adiponectin proteins (Fig. 3A). The IGF-1 treatment increased the phosphorylation of AKT, but this increase was suppressed by co-treatment with LY294002 or OSI-906, whereas the amounts of total AKT protein were unaltered (Fig. 3B). Therefore, IGF-1 appeared to induce adipocyte differentiation in HemSCs by upregulating the phosphorylation of AKT via an IGF-1R-PI3K signaling pathway.

\section{Discussion}

The cellular components of hemangiomas alter as their growth increases and subsides during their life cycle (1). Endothelial cells predominate in the proliferative phase but their numbers gradually decrease throughout the degeneration process (2). Adipocyte numbers increase and eventually dominate in the involuted phase. This accumulation of adipocytes is also reflected in the gene expression patterns in the involuting hemangioma (14). A number of genes associated with lipid metabolism are also overexpressed in the involuting hemangioma (14). This increased accumulation of adipocytes provides a novel perspective for the study of hemangiomas.

A previous study indicated the involvement of IGF in the differentiation of stem cells into adipocytes (12), but no studies have yet been performed on hemangioblast stem cells. The data presented here indicate that IGF-1 significantly and dose-dependently promotes in vitro proliferation and lipid accumulation in HemSCs, and that adipogenesis in these cells proceeds in response to known signaling pathways.

The process of adipogenesis is regulated by transcription factors, including the PPARs and CCAAT/enhancer binding protein (C/EBP) family members, which form a complex network of signaling pathways (15). PPAR $\gamma$ is a nuclear hormone receptor that serves a key role in adipogenesis. For example, its ectopic expression stimulates the differentiation of cultured fibroblasts (16) and a moderate reduction in PPAR $\gamma$ in mice prevents the obesity caused by high-fat diets (17). Numerous molecules serve a role in the regulation of adipogenesis through PPAR $\gamma$ (17-19). In the present study, it was identified that IGF-1 upregulated the expression levels of $\mathrm{PPAR} \gamma, \mathrm{C} / \mathrm{EBP} \alpha$ and $\mathrm{C} / \mathrm{EBP} \beta$, and increased lipid accumulation, as demonstrated by Oil Red $\mathrm{O}$ staining.

IGF-1 serves an important role in the proliferation and differentiation of various cells, including adipocytes (20). IGF-1 binds primarily to IGF-1R on the cell surface, and subsequent activation results in phosphorylation of the major substrate (21). The two major signal transduction pathways initiated by IGF-1/IGF-1R are mitogen-activated protein kinase (MAPK)/extracellular signal-regulated kinase (ERK) and PI3K/AKT. Previous studies have reported that the MAPK/ERK pathway stimulates 3T3-L1 preadipocyte proliferation, while its inhibition blocks IGF-1-stimulated mitosis, but not the differentiation of these cells $(18,22)$. Other studies have reported an influence of the PI3K/AKT component of the IGF-1/IGF-1R signaling pathway on adipose tissue differentiation, as treatment of 3T3-L1 preadipocytes with PI3K inhibitors results in a complete blockade of adipocyte differentiation $(23,24)$. The present findings indicated that IGF-1 potently stimulated HemSC proliferation and adipocyte differentiation, while treatment of HemSCs with the PI3K inhibitor LY294002 or the IGF-1R inhibitor OSI-906 suppressed the expression of $\mathrm{C} / \mathrm{EBP} \alpha, \mathrm{C} / \mathrm{EBP} \beta$, PPAR $\gamma$ and adiponectin induced by IGF-1. Treatment with LY294002 alone also suppressed adipocyte differentiation 

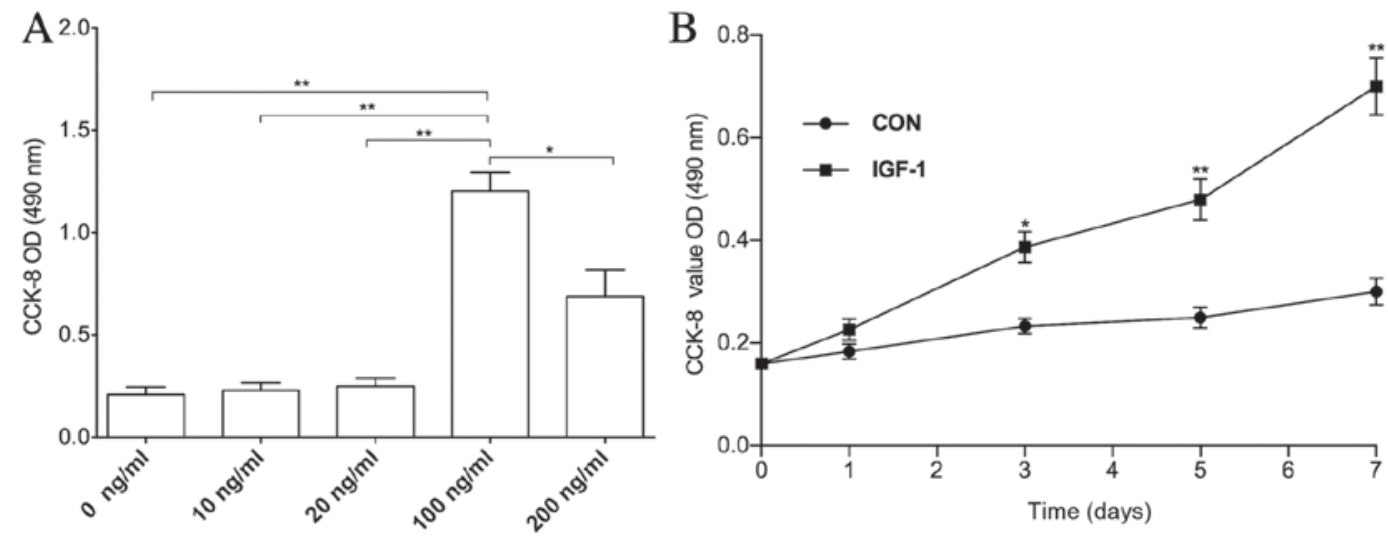

Figure 1. IGF-1 stimulates the in vitro proliferation of HemSCs. (A) Proliferation of HemSCs was enhanced by IGF-1 in a dose-dependent manner. IGF-1 at $100-200 \mathrm{ng} / \mathrm{ml}$ significantly promoted the proliferation of HemSCs when compared with the control group, and IGF-1 at $100 \mathrm{ng} / \mathrm{ml} \mathrm{induced}$ the greatest proliferation among all groups. (B) Growth curves of HemSCs treated with IGF-1. The proliferation of IGF-1-treated HemSCs (days 3-7) was promoted compared with the untreated group. Values are presented as the mean \pm standard deviation. $n=3 .{ }^{~} \mathrm{P}<0.05 ;{ }^{* *} \mathrm{P}<0.01$. CCK-8, Cell Counting kit-8; OD, optical density; CON, control; IGF-1, insulin-like growth factor-1; HemSCs, hemangioma stem cells.

A

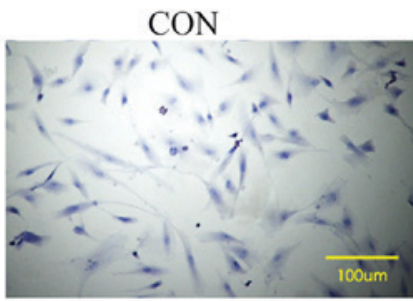

$\mathrm{B}$

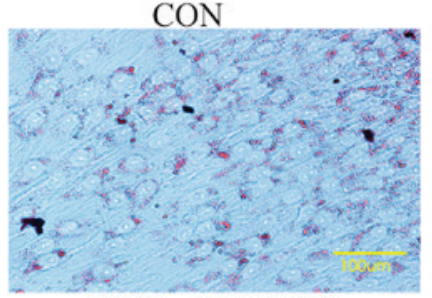

IGF-1+LY294002

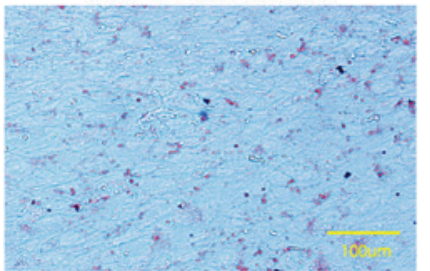

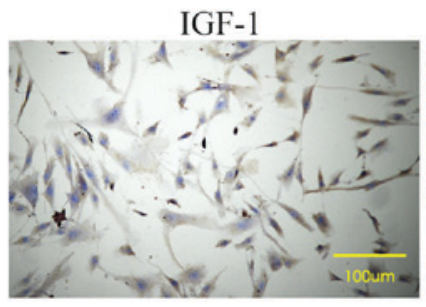

IGF-1

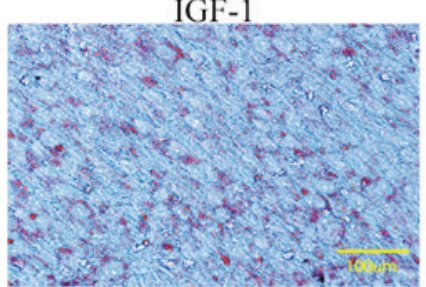

LY294002

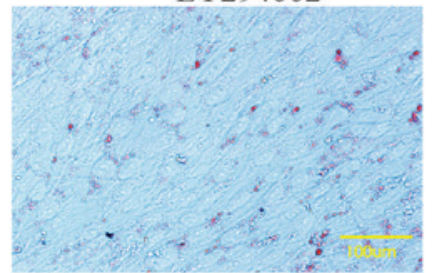

IGF-1R

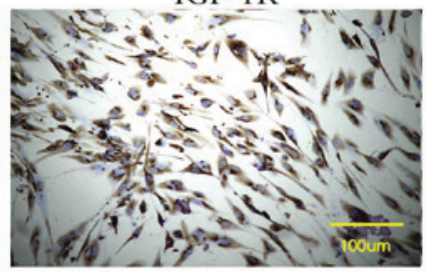

IGF-1+OSI-906
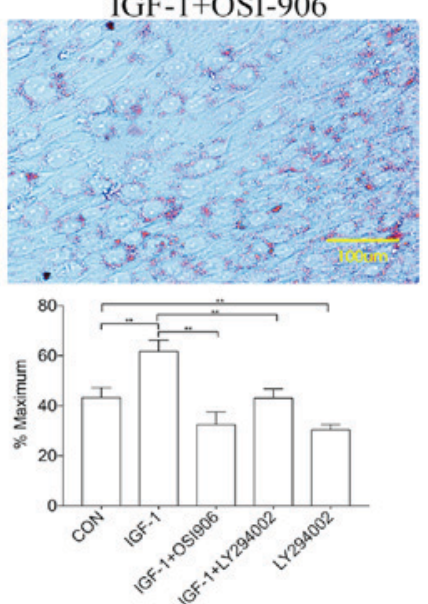

Figure 2. Expression of IGF-1 and its receptors in HemSCs, and the effect of IGF-1 on the adipogenesis of HemSCs. (A) Immunohistochemistry of HemSCs using antibodies specific for IGF-1 and IGF-1R. (B) IGF-1 was able to induce the differentiation of HemSCs into adipocytes. CON, HemSCs that were cultivated for 10 days in adipogenic differentiation medium; IGF-1, adipogenic differentiation medium with IGF-1 (100 ng/ml); IGF-1+OSI-906, adipogenic differentiation medium with IGF-1 (100 ng/ml) plus OSI-906 (1 $\mu \mathrm{M})$; IGF-1+LY294002, adipogenic differentiation medium with IGF-1 (100 ng/ml) plus LY294002 (1 $\mu \mathrm{M})$; LY294002, adipogenic differentiation medium with LY294002 (1 $\mu$ M). Following Oil Red O staining, phase-contrast microscopy was used to observe the lipid droplets. The Oil Red O-stained cells were quantified using Image J software. Data are expressed as the average percentage of the maximum signal \%. Values are presented as the mean \pm standard deviation. $n=3$. ${ }^{* *} \mathrm{P}<0.01$. CON, control; IGF-1, insulin-like growth factor-1; IGF-1R, IGF-1 receptor; HemSCs, hemangioma stem cells.

and the expression of these proteins. The IGF-1 treatment also promoted the phosphorylation of AKT, while treatment with OSI-906 or LY294002 suppressed this phosphorylation. These findings indicated that IGF-1 regulates the adipocyte differentiation of HemSCs from IH through the IGF-1R/PI3K/AKT pathway.

The present study had certain limitations. One is the small number of patients included in the study. In addition, only the in vitro effects of exogenous IGF-1 on adipogenesis in HemSCs were analyzed, and the study did not address endogenous or in vivo effects. Nevertheless, our findings indicated that IGF-1 was able to modulate the proliferation and differentiation of HemSCs, and that adipogenesis was enhanced by the IGF-1R and PI3K pathways. Therefore, IGF-1 serves an important role in fat formation in HemSCs arising from $\mathrm{IH}$ and may be of interest for the treatment of IH. 

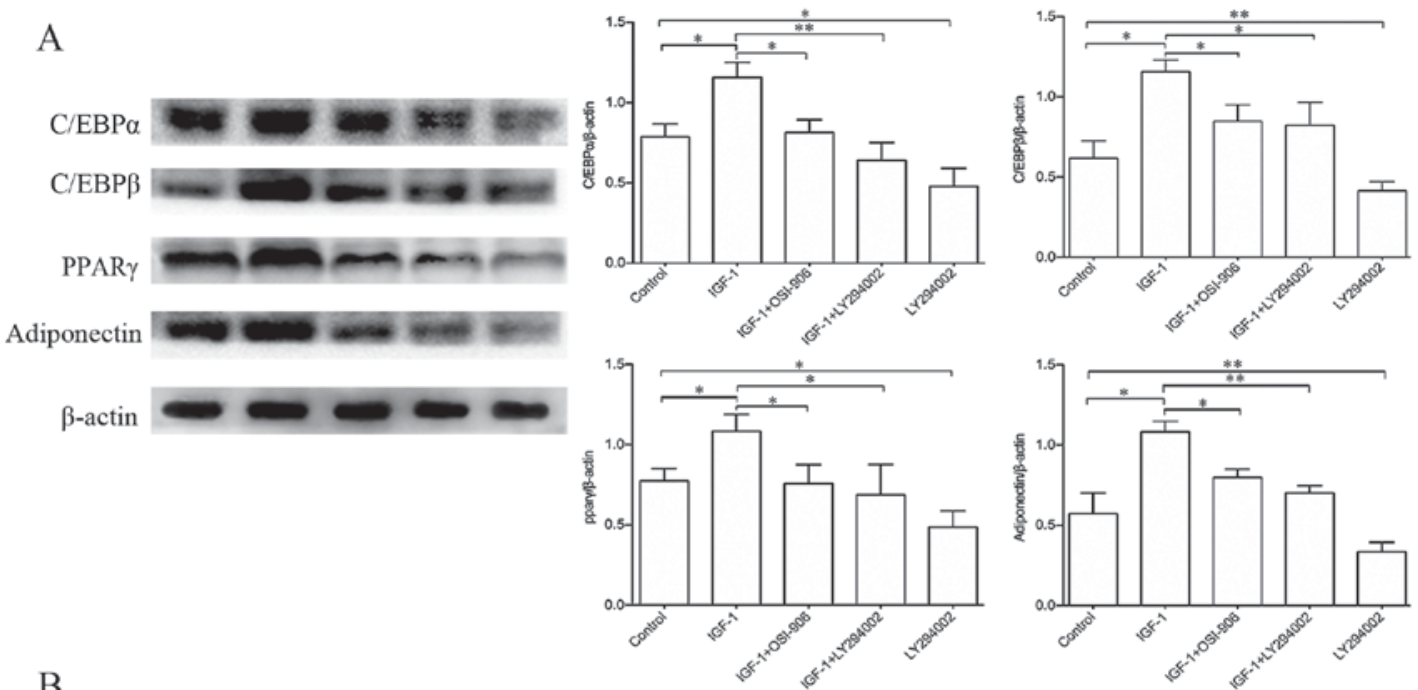

B
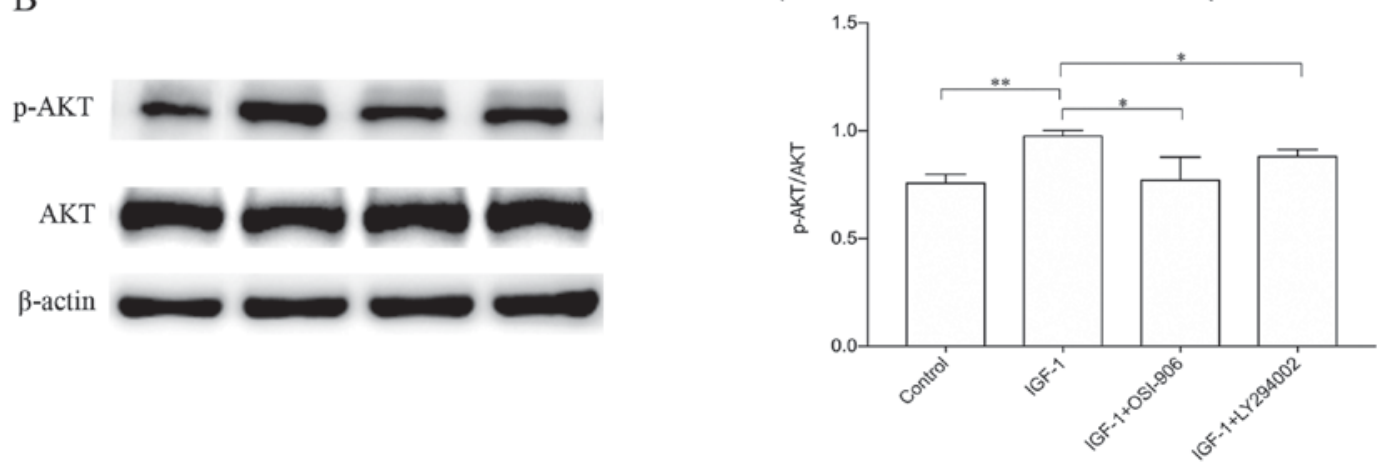

Figure 3. Effects of IGF-1 on the expression of adipogenic markers in HemSCs. The C/EBP $\alpha, C / E B P \beta$, PPAR $\gamma$ and adiponectin protein expression levels were analyzed by western blotting. (A) Western blot analysis demonstrating the protein expression levels of C/EBP $\alpha, \mathrm{C} / \mathrm{EBP} \beta$, PPARg and adiponectin in HemSCs treated with IGF-1 $(100 \mathrm{ng} / \mathrm{ml})$, IGF-1 $(100 \mathrm{ng} / \mathrm{ml})$ plus OSI-906 $(1 \mu \mathrm{M})$, IGF-1 (100 ng/ml) plus LY294002 (10 $\mu \mathrm{M})$, and LY294002 alone (10 $\mu \mathrm{M})$. $\beta$-actin was used as a loading control. (B) Western blot analysis demonstrating the expression levels of phosphorylated AKT (p-AKT) and total AKT in confluent HemSC cultures exposed to the indicated treatments for $1 \mathrm{~h}$. Quantification of the p-AKT protein expression levels indicated a significant increase in the IGF-1 group $(\mathrm{P}<0.05)$. No differences were detected in the total AKT protein levels among the groups. Values are presented as the mean \pm standard deviation. $\mathrm{n}=3 .{ }^{~} \mathrm{P}<0.05,{ }^{* *} \mathrm{P}<0.01$. IGF-1, insulin-like growth factor-1; HemSCs, hemangioma stem cells; C/EBP, CCAAT/enhancer-binding protein; PPAR $\gamma$, peroxisome proliferator-activated receptor- $\gamma$; AKT, RAC-a serine/threonine-protein kinase; p, phosphorylated.

\section{Acknowledgements}

The authors would like to thank the Central Laboratory of the Second Affiliated Hospital of Anhui Medical University.

\section{Funding}

The present study was funded by the Natural Science and Technology Fund Project of Anhui Province (grant no. $1808085 \mathrm{MH} 282$ ).

\section{Availability of data and materials}

The datasets used and/or analyzed during the current study are available from the corresponding author on reasonable request.

\section{Authors' contributions}

DC, XH, FW and HL conceived and designed the experiments. FW and HL performed the experiments. FW produced the manuscript. FW and HL conducted data analysis. YL, HL and JX provided tissue specimens. All authors read and approved the final manuscript.

\section{Ethics approval and consent to participate}

The study was approved by the Ethics Committee of the second Hospital of Anhui Medical University (no. PJ-bb2017-026). Written informed consent was obtained from the patients and/or guardians.

\section{Patient consent for publication}

Not applicable.

\section{Competing interests}

The authors declare that they have no competing interests.

\section{References}

1. Kilcline $\mathrm{C}$ and Frieden IJ: Infantile hemangiomas: How common are they? A systematic review of the medical literature. Pediatr Dermatol 25: 168-173, 2008.

2. Munden A, Butschek R, Tom WL, Marshall JS, Poeltler DM, Krohne SE, Alió AB, Ritter M, Friedlander DF, Catanzarite V, et al: Prospective study of infantile haemangiomas: Incidence, clinical characteristics and association with placental anomalies. Br J Dermatol 170: 907-913, 2014. 
3. Pandey A, Gangopadhyay AN and Upadhyay VD: Evaluation and management of infantile hemangioma: An overview. Ostomy Wound Manage 54: 16-18, 20, 22-26, 28-29, 2008.

4. Khan ZA, Boscolo E, Picard A, Psutka S, Melero-Martin JM, Bartch TC, Mulliken JB and Bischoff J: Multipotential stem cells recapitulate human infantile hemangioma in immunodeficient mice. J Clin Invest 118: 2592-2599, 2008.

5. Roach EE, Chakrabarti R, Park NI, Keats EC, Yip J, Chan NG and Khan ZA: Intrinsic regulation of hemangioma involution by platelet-derived growth factor. Cell Death Dis 3: e328, 2012.

6. Zhao P, Deng Y, Gu P, Wang Y, Zhou H, Hu Y, Chen P and Fan X: Insulin-like growth factor 1 promotes the proliferation and adipogenesis of orbital adipose-derived stromal cells in thyroid-associated ophthalmopathy. Exp Eye Res 107: 65-73, 2013.

7. Laviola L, Natalicchio A and Giorgino F: The IGF-I signaling pathway. Curr Pharm Des 13: 663-669, 2007.

8. Garten A, Schuster S and Kiess W: The insulin-like growth factors in adipogenesis and obesity. Endocrinol Metab Clin North Am 41: 283-295, v-vi, 2012.

9. Chen Q, Shou P, Zheng C, Jiang M, Cao G, Yang Q, Cao J, Xie N, Velletri T, Zhang X, et al: Fate decision of mesenchymal stem cells: Adipocytes or osteoblasts? Cell Death Differ 23 $1128-1139,2016$

10. James AW: Review of signaling pathways governing MSC osteogenic and adipogenic differentiation. Scientifica (Cairo) 2013 684736, 2013.

11. Tontonoz P, Hu E and Spiegelman BM: Regulation of adipocyte gene expression and differentiation by peroxisome proliferator activated receptor gamma. Curr Opin Genet Dev 5: 571-576, 1995.

12. Scavo LM, Karas M, Murray M and Leroith D: Insulin-like growth factor-I stimulates both cell growth and lipogenesis during differentiation of human mesenchymal stem cells into adipocytes. J Clin Endocrinol Metab 89: 3543-3553, 2004.

13. Yu Y, Wylie-Sears J, Boscolo E, Mulliken JB and Bischoff J: Genomic imprinting of IGF2 is maintained in infantile hemangioma despite its high level of expression. Mol Med 10: 117-123, 2004.

14. Yu Y, Fuhr J, Boye E, Gyorffy S, Soker S, Atala A, Mulliken JB and Bischoff $\mathrm{J}$ : Mesenchymal stem cells and adipogenesis in hemangioma involution. Stem Cells 24: 1605-1612, 2006.
15. Kubota N, Terauchi Y, Miki H, Tamemoto H, Yamauchi T, Komeda K, Satoh S, Nakano R, Ishii C, Sugiyama T, et al: PPAR gamma mediates high-fat diet-induced adipocyte hypertrophy and insulin resistance. Mol Cell 4: 597-609, 1999.

16. Siersbaek R, Nielsen R and Mandrup S: PPARgamma in adipocyte differentiation and metabolism-novel insights from genome-wide studies. FEBS Lett 584: 3242-3249, 2010.

17. Zhang $\mathrm{C}$, Zhang $\mathrm{X}$, Ma L, Peng $\mathrm{F}$, Huang J and $\mathrm{Han} \mathrm{H}$ Thalidomide inhibits adipogenesis of orbital fibroblasts in Graves' ophthalmopathy. Endocrine 41: 248-255, 2012.

18. Boney CM, Gruppuso PA, Faris RA and Frackelton AR Jr: The critical role of Shc in insulin-like growth factor-I-mediated mitogenesis and differentiation in 3T3-L1 preadipocytes. Mol Endocrinol 14: 805-813, 2000.

19. Hers I: Insulin-like growth factor-1 potentiates platelet activation via the IRS/PI3Kalpha pathway. Blood 110: 4243-4252, 2007.

20. Boney CM, Smith RM and Gruppuso PA: Modulation of insulin-like growth factor I mitogenic signaling in 3T3-L1 preadipocyte differentiation. Endocrinology 139: 1638-1644, 1998.

21. Boney CM, Sekimoto H, Gruppuso PA and Frackelton AR Jr: Src family tyrosine kinases participate in insulin-like growth factor I mitogenic signaling in 3T3-L1 cells. Cell Growth Differ 12: 379-386, 2001.

22. Smith TJ: Insulin-like growth factor-I regulation of immune function: A potential therapeutic target in autoimmune diseases? Pharmacol Rev 62: 199-236, 2010.

23. Peng XD, Xu PZ, Chen ML, Hahn-Windgassen A, Skeen J, Jacobs J, Sundararajan D, Chen WS, Crawford SE, Coleman KG and Hay N: Dwarfism, impaired skin development, skeletal muscle atrophy, delayed bone development, and impeded adipogenesis in mice lacking Akt1 and Akt2. Genes Dev 17: 1352-1365, 2003.

24. Xu J and Liao K: Protein kinase B/AKT 1 plays a pivotal role in insulin-like growth factor-1 receptor signaling induced 3T3-L1 adipocyte differentiation. J Biol Chem 279: 35914-35922, 2004. 